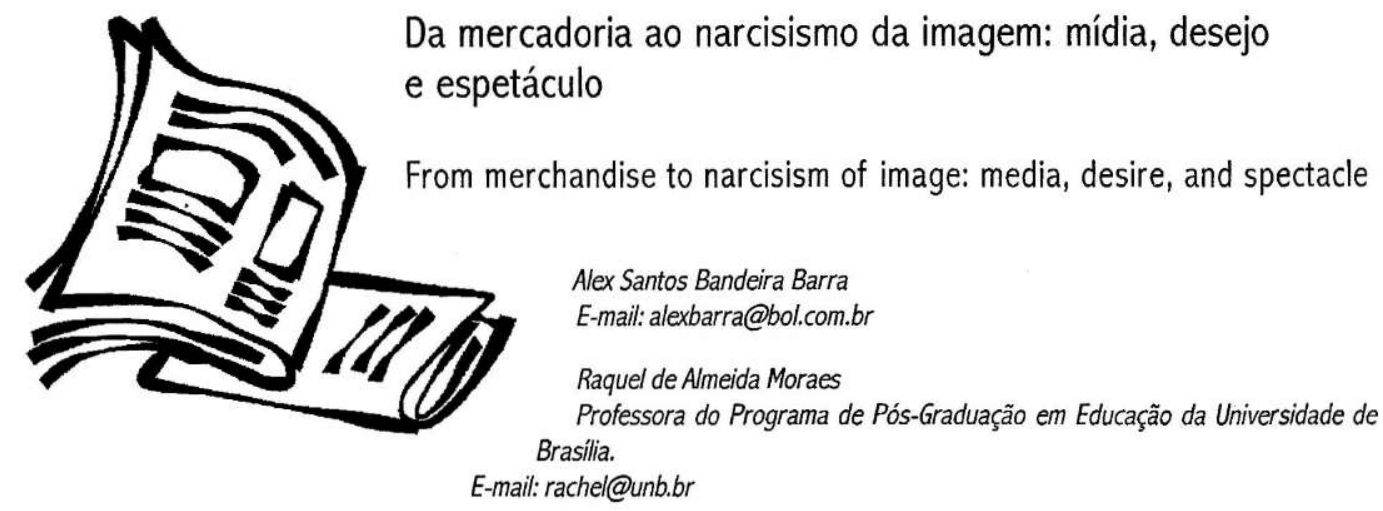

Resumo

0 presente artigo faz uma crítica aos meios de comunicação de massa manifestados a partir do declínio da autoridade, exacerbação do individualismo, consumismo e a perda do sentido ético e histórico da vida. Nosso argumento é que a mídia, como agente de comunicação, deve deixar o valor meramente de troca, instrumental e técnico do entretenimento e procurar difundir cultura e arte em seu sentido pleno.

Palavras-chave: Mídia, Formação, Narcisismo.

Introdução

O presente artigo analisa o papel da mídia na contemporaneidade. Para isso, sugerem-se quatro elementos de discussão: a relação comunicação e sociedade; mídia e capitalismo; narcisismo contemporâneo e o papel dos professores na análise dos meios de comunicação.

\section{Comunicação e sociedade}

Quanto mais se desenvolve a sociedade capitalista, mais há uma interpenetração entre os elementos sociais, econômicos e culturais. A mídia, em especial a que surgiu em meados da década de 1960, com a emergência dos países centrais após a Segunda Guerra Mundial, tem tido um papel central na difusão de idéias e ideologias nas relações sociais, econômicas e culturais atuais. A preocupação com a audiência, medida e controle dos telespec-tadores e ouvintes já se iniciara desde os anos 1960 e 1970, sobretudo nos EUA, e, com a popularização da cultura de massa, tem se intensificado cada vez mais. Antes eram a TV e o rádio, hoje é TV, rádio, cinema, internet $\mathrm{e}$ telecomunicações.

Grandes conglomerados da mídia têm sido criados. Corporações que antes eram nacionais, agora são internacionais ou planetárias, como as redes de TV e rádio CBS, Timer Warner Disney, estúdios Paramount, MTV, Nickelodeon e as locadoras de vídeo Blockbuster (Bagdikian, 1993; Moraes, 2000), incorporando diferentes processos midiáticos por meio do controle e da difusão de uma cultura mundializada (Ortiz, 2000), criando a sociedade do infoentretenimento. "Para vencer o mercado global ultracompetitivo, as corporações precisam fazer circular suas imagens e marca para que os negócios e publicidade se combinem na promoção de espectáculos midiáticos" (Kellner, apud Moraes 2006, p. 125). Se a globalização é fenômeno corrente na economia, as comunicações são o carro-chefe, "ela é um fator determinante da 
transformação cultural em curso, e se tornou o eixo central das transformações estruturais, tanto na economia como na politica" (Dowbor, 2000, p.58-59).

É evidente que os países centrais, como Estados Unidos e os da Europa, têm tido o papel de "dominar" a internacionalização social e cultural na expansão da comunicação, pois é lá que estão concentrados os grandes grupos midiáticos. Novos processos sociais emergem com a difusão da mídiạ. As mudanças nas "estruturas de poder, as tecnoestruturas, os thinktanks, os lobbies, as organizações multi-laterais e as corporações transnacionais, sem esquecer as corporações da mídia" (Ianni, 2000, p.143).

A própria definição e complexidade do mundo atual chamam atenção, pois predominam discursos e teorias que questionam por qual momento da história estamos passando. Se modernidade ou pósmodernidade (Rouanet, 1985), se uma sociedade do trabalho (Antunes, 2000) ou da informação (Castells, 1999). Os nomes e as terminologias são variados para caracterizar a sociedade atual, embora não haja dúvida de que uma terceira revolução industrial tem modificado a sociedade com o advento da microeletrônica (Benakouche, 1985; Schaff, 1985), cujas mudanças no sistt:ma produtivo produzidas por máquinas informatizadas indicam que as tecnologias da inteligência têm imperado. As transformações que se iniciam na indústria com o incremento da máquina "leve", em contraposição às antigas máquinas, "pesadas", braçais, são agora programadas para aumentar a eficiência, diminuir os custos e produzir mais. Com isso, a chamada "sociedade informática" parece ser a coqueluche do momento, com $o$ incremento da indústria da informação em todos os setores da vida, o que atinge a economia, a política, a cultura e a educação.

Parece que o mundo atual é um mundo que mais valoriza o passageiro, o descartável, o efềmero, o instável, o particular, em detrimento do duradouro, do universal, do lógico, do histórico (Chaú, 2001). As idéias pertencentes a um discurso e a uma compreensão universal das coisas são transformadas numa ordem particular, cotidiana, subjetivista, psicologista. Contra essa postura (ou impostura) teórica é necessário enfatizar quais possibilidades existem de um entendimento lógico e histórico do mundo.

A chamada sociedade pósmoderna, de caráter instável e efêmero, tem alimentado a indústria que divulga uma cultura popularizada e banalizada, "menos artística", em que a noção de arte é a daquela que adere às determinações técnicas do capital, em que se perde o valor de contestação e crítica social (Adorno, 1985). Num mundo onde a fetichização das relações sociais virou regra, em que de cidadão, o sujeito, passa a consumidor, nos parece ser essencial questionar qual o papel da mídia e, em consequiência, o papel do professor na realidade escolar.

Mídia e Capitalismo: da produção ao consumo

Independentemente de haver ou não uma adequada distribuição da cultura ou se ela própria preserva o desenvolvimento local (Ortiz, 2000), o que se vê é uma expansão mundial do desenvolvimento e da difusão cultural, integrando todos e tudo ao mesmo gosto, vestimenta, opiniões, etc. Percebe-se isso pela padronização da cultura, mediante aquilo que ficou conhecido como Indústria Cultural (Adorno e Horkheimer, 1985), e cujo conceito tem sido 
atualizado como Indústria Cultural Global (Duarte, 2003).

No geral, percebe-se a difusão de bens culturais tornados entretenimento. Vivemos, assim, numa sociedade midiatizada. Tudo é objeto de consumo e, como tal, veiculado pela mídia, até os telejornais que, em vez de noticiarem informações que esclarecem, incrementam a lógica do espetáculo na divulgação da notícia.

O que explica essa espetacularização pode ser compreendido por algumas categorias e alguns conceitos marxistas. O fetiche das mercadorias (Marx, 1985), por exemplo, serve para explicitar o que tem ocorrido. Vivemos numa sociedade em que as determinações sociais da particularidade histórica modificam aquilo que poderia servir a todos (universalidade). O histórico, particular, definido, transforma o universal, indefinido. Isso faz crer que aquilo que vivemos é natural e a-histórico, como propagandeado pela ideologia contemporânea.

No caso da cultura, as mudanças e transformações são substanciais. Se a mercadoria serve para ser consumida por todos, ela é transformada num fetiche em que suas necessidades são minimizadas em prol de um valor criado, não mais no uso, mas no valor fetichizado. A mercadoria deixa de ter valor de uso e transforma-se em valor de troca (Marx, 1985). Ao invés de as mercadorias dependerem de nossas necessidades são as nossas necessidades que dependem da mercadoria (Carone, 2001).

Isso tem implicações sociais, políticas, psicológicas e educacionais. De uma necessidade social, cada vez mais pública, passamos a atender às mudanças privadas $\mathrm{e}$ íntimas, com a conseqüente fetichização das relações sociais. Significa que o indivíduo é, cada vez mais, solicitado a "expor" aquilo que antes era guardado, privado, individual, psíquico. Ou seja, inverte-se a relação: o que é público é privatizado e o que é privado é publicizado. Troca-se o culto pela exposição (Benjamin, 1994).

Os programas de entretenimento na televisão, por exemplo, expõem cada vez mais essa tendência de transformar as coisas e as pessoas em espetáculos. Em vez de o artista falar de seu trabalho e do que pensa sobre arte, ele conta o que faz em casa, onde mora, com quem namora e se diverte. Transforma-se opinião em curiosidade. Transforma-se o real da essência em real da aparência. Se antes o que importava era ser, passou-se para o ter e, atualmente, $o$ que importa é o parecer (Debord, 1999).

Uma outra questão é a da produção e do consumo. A cultura é algo que, muitas vezes, consumimos mediante nossa produção, pois produção e consumo, nesse sentido, não se separam. Atualmente, só se consome e só se reproduz. $\mathrm{O}$ valor das mercadorias, cada vez mais, atende à venda. A lógica da produção é transformada em lógica produtivista. A cultura transforma-se em atividade não mais "plena", valorizada pelo seu valor de uso, mas como um valor puramente mercantil. Vemos essa mesma lógica na mídia, que menos se preocupa com a difusão de objetos de cultura "universais", veiculando, ao contrário, uma cultura padronizada sustentada pela audiência e sua possibilidade de compra e venda no mercado. Assim, o verdadeiro transforma-se em falso. A qualidade transforma-se em quantidade. A idéia de cultura, que em seu interior pode significar liberdade, se perde numa "redoma de cristal que, por se desconhecer, julga-se liberdade. E essa consciência falsa amalgama-se 
por si mesma à igualmente falsa e soberba atividade do espírito" (Adorno, 1996, p.391).

Isso significa que o sujeito deixa de se reconhecer universalmente naquilo que é produzido. Em vez de exteriorizar suas capacidades cognitivas, afetivas e sociais, ele não mais se reconhece. A função da arte é levar o sujeito da condição psicológica, singular e empírica à condição de sujeito universal, concreto, absoluto (Hegel, 1999). Isso não ocorre hoje. Porque, como mencionado antes, os processos históricos ou particulares têm se sobreposto ao universal. Nesse sentido, a arte deixa de ter a função plena e se transforma em pura afirmação da lógica produtiva (Adorno, 1985). Nem é necessário discutir a necessidade de uma outra arte, aquela que dará um outro contorno a esse controle econômico. Também tem o outro lado, pois não se quer dizer que toda obra de arte sofre o abalo sísmico da determinação capitalista.

E por que o sujeito não tem se reconhecido? Porque a divisão do trabalho instalado no capitalismo obriga o sujeito à lógica fragmentária, em que está em questão o tudo e não o todo. Significa que o sujeito está mais preocupado com os meios do que com os fins (Horkheimer, 2002) Aqui entra a noção de racionalidade instrumental (Adorno e Horkheimer, 1985). As implicações sociais, culturais, psicológicas e educacionais são diversas. Primeiro, porque a fetichização da técnica ou a redução do sujeito às determinações da lógica produtivista obrigam cada vez mais uma redução ao puramente técnico.

Então, como dissemos anteriormente, em vez de o indivíduo consumir algo por sua "necessidade", que, na verdade, poderia ser chamado de desejo, ele o faz pela aparência, pela quantidade, por consumismo. Nesse sentido, predomina o controle, a dominação dos objetos, e não o gosto, a plenitude. Isso equivale a dizer que o sujeito, em vez de comprar por uma vontade em que ele próprio está se reconhecendo, ele compra porque os "outros" também o fazem. Há uma banalização social e subjetiva. $\mathrm{O}$ indivíduo, em vez de consumir por autonomia, consome por aquilo que os outros estão fazendo (cotidiano) e dizendo (mídia). Não há autonomia nem emancipação.

Para fechar essa questão. A cultura, nomeação complexa e cheia de significados, ainda assim deve ser difundida na sociedade. A mídia é parte da sociedade (não é seu todo, como a ideologia faz crer) e tem que propiciar isso. Seja a televisão, o rádio, o cinema, a imprensa, a internet. $\mathrm{O}$ consumo de um produto massificado, na atualidade, tem de ser transformado por um consumo reconhecido.

Hoje, se conhece demais e se reconhece pouco. Talvez as idéias de Adorno e Horkheimer na Dialética do Esclarecimento (1985), embora um tanto pessimistas, sirvam para nos alertar disso. $\mathrm{O}$ homem na sociedade moderna perde, ganhando. Ele perde a si mesmo no exato instante em que controla e determina as coisas e as pessoas. Se, em vez de perder, ele pedir, isto é, reconhecer, talvez um passo importante tenha sido dado, seja social, seja psicologicamente. No caso da cultura é a mesma coisa: o indivíduo contemporâneo é bajulado e "influenciado" pela mídia, como uma mônada controlada e sem alternativas críticas ou psíquicas para questionar. Enfim, as pessoas têm perdido a capacidade de aprender umas com as outras. Esse talvez seja o primeiro passo em direção a uma formação cultural. 
Narcisismo contemporâneo: o Eu publicizado

Quando se fala de fetichização do indivíduo, várias questões podem ser apontadas. Primeiro, o corpo é a parte mais acentuada do fetichismo. A prova disso é que quando a mídia decide espetacularizar qualquer atividade "cultural" a melhor maneira que faz é pelo corpo, pela sensualidade, pelo erotismo, algo que é, inclusive, criticável, porque é pornográfico, não é erótico. Entende-se que o pornográfico não é artístico, enquanto o erotismo é universal, pois trabalha a arte de maneira disfarçada e integradora.

Vemos isso, hoje, quase todos os dias, seja pela banalização do corpo, da música e da imagem. No corpo, pela exacerbação da imagem feminina, por exemplo. Na música, pela coreografia, retrógrada e mimética, e não elaborativa, como em determinadas músicas Tecno. A dança tem servido para cansar, e não para integrar os corpos à harmonia. A harmonia é substituída pela desarmonia. E na imagem vemos a notícia que a transforma em espetáculo. "Uma imagem vale mais que mil palavras". Hoje, as palavras foram suprimidas. $\mathrm{O}$ que vale é a imagem por ela mesma.

$\mathrm{O}$ indivíduo torna-se a reprodução das mercadorias no contexto das imagens, agora projetadas pelas fantasias do eu. "A produção de mercadorias e o consumismo alteram as percepções não apenas do eu como do mundo exterior ao eu; criam um mundo de espelhos, de imagens insubstanciais, de ilusões cada vez mais indistinguíveis da realidade" (Lasch, 1986, p.22).

Talvez, por isso, valha mais a pena os "quinze segundos de fama" nos programas de auditório. Do ponto de vista psicológico, impera a rotina do narcisista, que "olha para .os outros para validar seu senso do eu. Precisa ser admirado por sua beleza, encanto, celebridade ou poder - atributos que geralmente declinam com o tempo" (Lasch, 1983, p. 254). O ideal de sucesso, do culto à beleza caminha na mesma direção do imediatismo do presente. As relações sociais são transformadas em ações do presente, sem preocupação com o passado. "Quando os homens se vêem incapazes de se interessar pela vida terrena após sua própria morte, desejam eles a eterna juventude, pela mesma razão por que não mais cuidam de se reproduzir" (Lasch, 1983, p. 255).

Isso é o que justifica o culto ao corpo em desfiles, na valorização dos músculos, etc. Cuidar não é mais sinônimo de "cuidado", isto é, valorização da vida. Ao invés, temse um prazer sádico, e não sadio. Ao invés de elaboração, tem-se catarse. A degradação do trabalho e o empobrecimento da vida comum obrigam as pessoas a experimentarem novas sensações prazerosas, cultuadas pela excitação sexual na tentativa de satisfação das necessidades emocionais (Lasch, 1983). Hoje, para os adolescentes, os programas de diversão são mais violentos e a proximidade com a agressividade é a expressão mais emocionante.

Do ponto de vista social, nos livramos das pressões externas que os curiosos, os vizinhos, as pessoas mais velhas exerciam sobre nós. Em contraposição, houve um empobrecimento da vida privada, pois os limites internos, as compulsões e as ansiedades são individualizadas. A fantasia deixa de ser liberadora quando ela se solta dos controles impostos pela experiência prática do mundo. Em vez disso, ela dá lugar às alucinações. Isso tem uma implicação negativa nas relações 
sociais, pois hoje o desrespeito aos mais velhos mostra a dificuldade de relacionamento com a tradição, essencial para a transmissão cultural.

Comunicação e Processos Educativos: 0 papel do professor

Não é possível haver, discutir o papel do professor descontextualizado do papel da educação, o que não quer dizer, todavia, que a educação se traduza necessariamente no trabalho do docente ou mesmo na própria prática escolar, pois, como se sabe, a escola na sociedade capitalista tem seguido a direção de uma classe que precisa ser educada (Saviani, 1994). A escola tem servido aos interesses da classe dominante.

O papel do professor, mais simples do que a complexidade de significados da escola, é o de formar os alunos, seja nos aspectos objetivos ou subjetivos. Objetivos, pertencentes aos conteúdos a serem ministrados, e adequados à direção da competência técnica que o docente deve ter para ministrar sua disciplina e à própria formação de um modo geral. Retirar o aluno da condição de sujeito empírico em direção ao sujeito concreto (Saviani, 2003). Isto é, a criança precisa ser informada. Ela vai para a escola para aprender. Aprender, no entanto, embora seja uma função essencialmente cognitiva, não se reduz às funções intelectuais.

Quando se fala de aprendizagem, pode-se incluir entre suas funções também outras esferas formativas importantes, como a moral, a afetividade, a estética, o desenvolvimento físico, etc. Ou seja, a escola e o docente também têm de se preocupar com as atividades subjetivas da criança. Na verdade, a socialização que parte do empírico e tem como ponto de chegada o concreto passa por isso: $\mathrm{O}$ aluno aprende a conviver com os demais, aprende a administrar regras, internaliza noções de autoridade, respeito, diferenças, etc. É claro que outras agências educativas, como a família, a igreja, a comunidade não estão fora desse processo, embora a escola seja, atualmente, a agência mais importante nessas funções. E como fica o papel do professor no

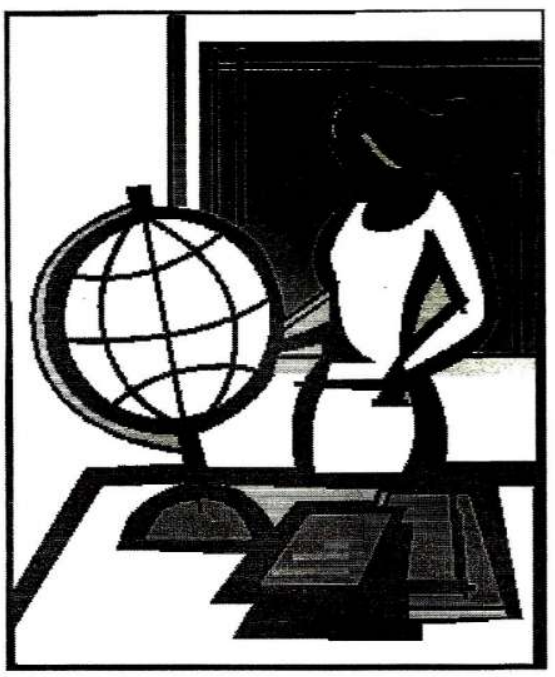
contexto da mídia?

Para os professores, não basta que "disponham, na escola, dos meios de comunicação ou apenas saberem usá-los. É preciso que aprendam a elaborar e a intervir no processo comunicacional que se realiza entre professores e alunos por meio de mídias" (Libâneo, 2004, p.71). E estamos destacando os aspectos formativos da mídia, que, como se sabe, além de informar, forma.

\section{Considerações finais}

Uma das funções da educação e do professor é incentivar uma formação crítica (Moraes, 2001). Neste artigo nós indicamos que deve ser plena, isto é, que o aluno se reconheça não apenas com imagens, mas com imaginação. Hoje se têm muitas imagens e pouca imaginação. É a prova do fetiche da técnica, que, com a entrada das tecnologias na escola, favorece o controle, quando deveria estar propiciando mais busca pela sabedoria. Os filmes, nesse caso, desem-penham um papel imprescindível, pois podem oferecer uma formação cultural de 


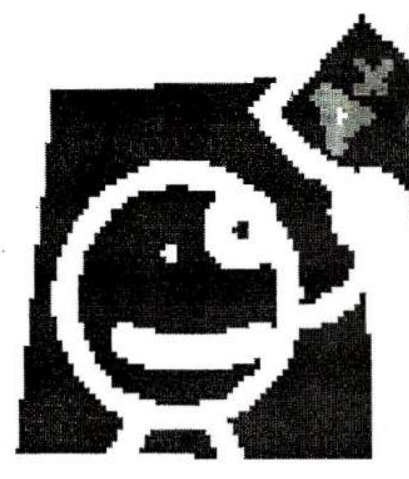

ordem mais estética e menos cognitiva, o que não deixa de ser um aprendizado, aliás, de maneira socialmente mais interessante.

$\mathrm{Na}$ interação professor e aluno, na qual os processos sociais, afetivos, cognitivos estão em questão, isso pode ser mais bem resolvido. Primeiro, porque o papel do professor e dos demais agentes escolares é difundir autoridade. É evidente que sua função é mais ampla e mais complexa. Mas a autoridade é parte substancial das apropriações subjetivas da criança. Se a educação de hoje é excessivamente permissiva, "é proibido reprimir", então, cabe ao educador contornar essa situação. E quando se fala em contornar a situação, não é aceitar todos os "desejos" da criança. Porque a ausência da autoridade é um dos piores males que a educação e o professor podem cometer, coisa que, aliás, tem sido vista com bastante freqüência em muitas escolas na atualidade.

Acreditamos que o papel do professor e da mídia, nesse sentido, é dar uma direção aos alunos nas apropriações objetivas e subjetivas. Objetivas, pela crítica e diálogo dos processos midiáticos. A mídia não pode servir apenas como atividade extra-escolar. Do ponto de vista subjetivo, mediante a relação professor e aluno, pois, como se sabe, o professor ocupa um lugar importante na vida das crianças e é papel da escola utilizar, de maneira mais participativa, esse lugar, dado, inclusive, pelos próprios alunos.

A arte ou cultura entra nesse lugar onde os processos relativos ao embate professor e aluno se processam, em que a curiosidade, a crítica, a criatividade devem imperar. O saber pedagógico é importante. Mas ele não pode estar descontextualizado do saber educativo, de uma instituição social, política e psicossocial importante como a mídia.

\section{Abstract}

The present article presents a critic to mass medias from the perspective $s$ of the decline of authority, exacerbation of individualism, consumerism and the loss of the ethical and historical sense of life. Our argument is that the media, as comunication agent, should leave the value merely of change, instrumental and technical of the entertainment and try to diffuse culture and art in its full sense.

Keywords: Media, Formation, Narcissism.

\section{Referências}

ADORNO, T. \& HORKHEIMER, M. Dialética do Esclarecimento. Trad. Guido Antônio de Almeida. Rio de Janeiro: Jorge Zahar Editor, 1985.

ADORNO, T. Educação e Emancipação. Trad. Wolfang Leo Maar. 2 ed.. São Paulo: Paz e Terra, 2000.

Teoria da Semicultura. Trad. Newton Ramos-de-Oliveira, Bruno Pucci, Cláudia B. Moura Abreu (coop. Paula Ramos de Oliveira). Educação \& Sociedade: revista quadrimestral de ciência da educação, Campinas, ano XVII (56), dez./1996.

ANTUNES, Ricardo. (org.). Adeus ao trabalho? Ensaio sobre as metamorfoses $e$ a centralidade do mundo do trabalho. 5 ed.. São Paulo: Cortez, 1998.

BAGDIKIAN, Ben. H. O Monopólio da Mídia. Tradução de Maristela M. de Faria Ribeiro. São Paulo: Scritta, 1993.

BENAKOUCHE, Rabah (org.). A questão da informática no Brasil. São Paulo: Brasiliense, CNPq, 1985.

BENJAMIN, Walter. Obras escolhidas. Vol. I: magia e técnica, arte e política. São Paulo: Brasiliense, $7^{\circ}$ Edição, 1994.

CASTELLS, Manoel. A Era da Informação: Economia, Sociedade e Cultura. Rio de Janeiro, 
Paz e Terra, 1999.

CHAUI, Marilena. Escritos sobre a universidade. São Paulo: Unesp, 2001.

CARONE, Iray. A Dialética Marxista: uma leitura epistemológica. In: LANE, S. \& CODO, W. (org.). Psicologia Social: o homem em movimento. Săo Paulo: Brasiliense, 3 reimpressão, 2001. DEBORD, Guy. A Sociedade do Espetáculo. Tradução por Estela dos Santos Abreu. São Paulo: Contraponto, $3^{\circ}$ reimpressão, 2002. DOWBOR, Ladislau. Economia da comunicação. DOWBOR, L (org.). Desafios da comunicação. Petrópolis, RJ: Vozes, 2000.

DUARTE, Rodrigo. Teoria Crítica e Indústria Cultural. Belo Horizonte, MG: Editora UFMG, 2003.

HORKHEIMER, Max. Eclipse da Razão. São Paulo: Centauro, 2002.

IANNI, Octávio. Enigmas da ModernidadeMundo. Rio de Janeiro: Civilização Brasileira, 2000.

KELLNER, Douglas. Cultura da Midia e triunfo do espetáculo. MORAES, Denis (org.). Sociedade Midiatizada. Traduções de Carlos Frederico Moura da Silva, Maria Inês Coimbra Guedes, Lúcio Pimentel. Rio de Janeiro: Mauad, 2006. LASCH, Cristophe. A Cultura do Narcisismo: a vida americana numa era de esperanças em declínio. Tradução por Ernani Pavaneli. Rio de Janeiro: Imago, 1983.

. Minimo Eu: sobrevivência psiquica em tempos dificeis. Tradução por João Roberto Martins Filho. 2 ed., São Paulo: Brasiliense, 1986.

LIBÂNEO, José Carlos. Adeus professor, adeus professora? Novas exigências educacionais e profissão docente. 8 ed., São Paulo: Cortez, 2004.

MARX, Karl. Manuscritos Econômico-Filosóficos. Tradução por Alex Marins. São Paulo: Martin Claret, 2002.

0 Capital. Vol. I. Tradução por

Edgar Malagodi, Leandro Konder, José Arthur Giannotti, Walter Rehfeld. São Paulo: Abril Cultural. Coleção os Economistas, 1985.

MATTELART, Armand. História da sociedade da informação. São Paulo: Loyola, 2002.

MORAES, Denis. A comunicação sob domínio dos impérios multimidias. DOWBOR, L. (org.). Desafios da comunicação. Petrópolis, Rio de Janeiro: Vozes, 2000.

MORAES, Raquel de A Mídia e Educação. PEDROSO, L. \& BERTONI, L. Indústria Culturale Educação (reflexões críticas). Araraquara, São Paulo: Unesp \& JM, 2002, p. 91-102.

ORTIZ, Renato. Mundialização e Cultura. São Paulo: Brasiliense, 2000.

ROUANET, Sérgio .P. As Razões do llumínismo. São Paulo: Companhia das Letras, 1987.

SAVIANI, Dermeval. Escola e Democracia. 36 ed.. São Paulo: Autores Associados, 2003. . 0 trabalho como principio educativo frente às novas tecnologias. FERRETTI, Celso João [et al]. Novas tecnologias, trabalho e educação: um debate multidisciplinar. 5 ed.. Petrópolis, Rio de Janeiro: Vozes, 1994. SCHAFF, Adam. Sociedade Informática. São Paulo, Unesp \& Brasiliense, 1985.

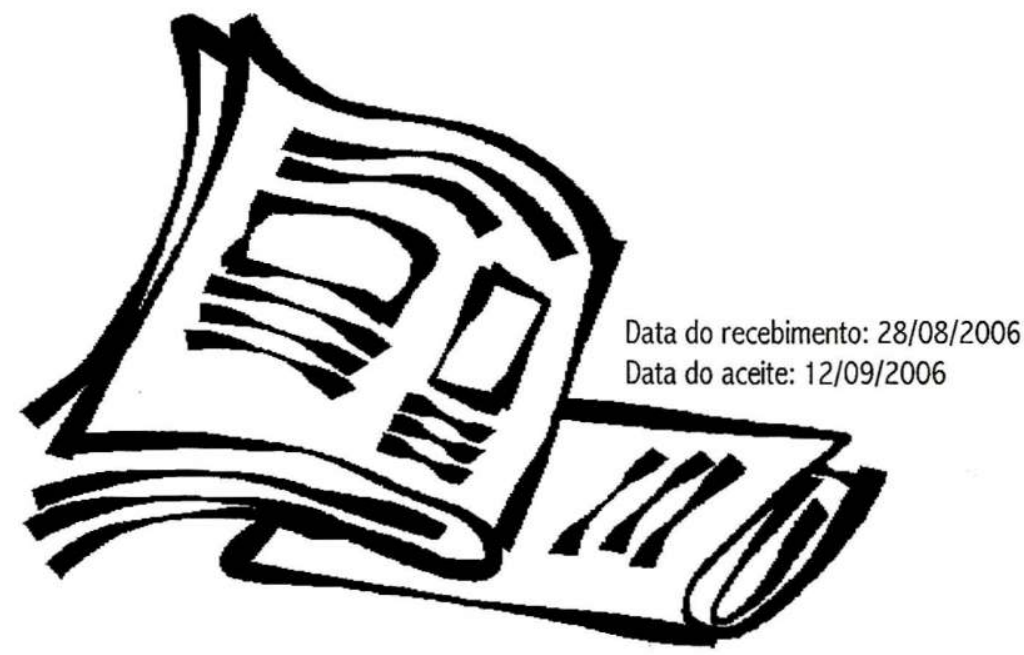

Alex Santos Bandeira Barra. Da mercadoria ao narcisismo da imagem: mídia, desejo e espetáculo. Comunicação e Informação, V 9, n² 2: pág 156 - 163 -jul/dez. 2006. 